\title{
Curcumin inhibits hypoxia-induced proliferation and invasion of MG-63 osteosarcoma cells via downregulating Notch1
}

\author{
ZHAN WANG, KUN ZHANG, YANGJUN ZHU, DENGFENG WANG, YUXIONG SHAO and JUN ZHANG
}

Department of Orthopaedics, Hong Hui Hospital, Xi'an Jiaotong University School of Medicine, Xi'an, Shaanxi 710054, P.R. China

Received November 6, 2015; Accepted November 11, 2016

DOI: $10.3892 / \mathrm{mmr} .2017 .6159$

\begin{abstract}
Curcumin is a biologically active ingredient abundantly present in the ground rhizomes of Curcuma longa with a wide range of bioactive properties, including antitumor effects. Hypoxia is a common characteristic of solid tumors, including osteosarcoma. However, whether curcumin has antitumor effects on osteosarcoma under hypoxic conditions, and its underlying molecular mechanisms, remain unclear. The present study demonstrated that the MG-63 osteosarcoma cell line exhibited increased proliferation and enhanced invasiveness upon exposure to hypoxic conditions. However, these effects were prevented by curcumin treatment. Further investigation revealed that curcumin may inhibit Notch1 upregulation induced by hypoxia. Overexpression of Notch1 via Notch1 cDNA transfection ameliorated curcumin-inhibited MG-63 cell growth under hypoxic conditions. Taken together, these data revealed that curcumin may suppress the growth of osteosarcoma cells in hypoxia via inhibiting Notch1 signaling.
\end{abstract}

\section{Introduction}

Osteosarcoma is the most common type of primary malignant bone cancer in children and adolescents, accounting for $\sim 35 \%$ of all bone cancers (1). One of the most prominent characteristics of osteosarcoma is local invasiveness and distant metastatic ability, which influences the therapy options and prognosis of the disease. With the use of neoadjuvant chemotherapy, the 5-year survival rate for non-metastasized cases has improved from 60 to $70 \%$. However, the 5-year survival rate of patients with metastasis remains $<30 \%$ (2). Thus, novel

Correspondence to: Dr Jun Zhang, Department of Orthopaedics, Hong Hui Hospital, Xi'an Jiaotong University School of Medicine, 555 East Youyi Road, Xi'an, Shaanxi 710054, P.R. China

E-mail: wangzhan252@126.com

Abbreviations: HIF-1 $\alpha$, hypoxia inducible factor- $1 \alpha$; NICD, Notch intracellular domain

Key words: osteosarcoma, hypoxia, Notch1, hypoxia inducible factor-1 $\alpha$, normoxic therapeutic targets and strategies are required to improve the outcome in patients with osteosarcoma.

Hypoxia, caused by a limited blood supply from aberrant neovascularization and a rapidly growing tumor mass, is a common characteristic of solid tumors (3). Hypoxic conditions are hypothesized to facilitate tumor progression by activating signaling pathways involved in cell proliferation, angiogenesis, apoptosis, invasion and metastasis (4). The transcription factor hypoxia-inducible factor- $1 \alpha$ (HIF-1 $\alpha)$ is a key element in the cellular response to hypoxia and is widely expressed in a variety of solid tumors, including osteosarcoma (5). Previous studies have demonstrated that HIF-1 $\alpha$ expression levels are significantly associated with vascular endothelial growth factor and cyclooxygenase- 2 expression levels in osteosarcoma tissues (6). Furthermore, overexpression of HIF-1 $\alpha$ is predictive of poor prognosis in osteosarcoma patients (7). Thus, HIF-1 $\alpha$-targeted therapy may offer a novel strategy for the treatment of osteosarcoma.

The Notch signaling pathway is an evolutionarily conserved signaling pathway. The aberrant expression and activation of Notch signaling has been demonstrated in various types of malignancies and has been associated with cell proliferation, survival, apoptosis and differentiation (8). To date, four Notch receptors have been identified in mammals, Notch1-4. The binding of a ligand (jagged 1, jagged 2, delta-like 1 or delta-like 4) to cell-surface Notch1-4 results in the cleavage and nuclear translocation of the Notch intracellular domain (NICD), leading to the expression of downstream targeting genes (9). A previous study indicated that Notch1 is a downstream signaling component of HIF-1 $\alpha$ under hypoxic conditions (10). However, whether Notch1 inhibition may reverse the effects induced by hypoxia remains to be clarified.

Curcumin is a biologically active ingredient abundantly present in the ground rhizomes of Curcuma longa, which is widely distributed in Southeast Asia (11). The wide range of bioactive properties of curcumin have been known for a number of years, and include anti-oxidative (12), anti-inflammatory (13), anticoagulative (14) and anti-atherosclerotic (15) properties. The antitumor effect of curcumin is of increasing interest (16-19). It has been reported that curcumin may exert antitumor effects in normoxic and hypoxic conditions (4). As hypoxia is a key characteristic of the tumor microenvironment in osteosarcoma, the identification of molecules that contribute to the antitumor effects of curcumin may provide potential therapeutic targets. The present study investigated the effects 
of curcumin on the biological behaviors of osteosarcoma cells in a hypoxic microenvironment and the potential underlying molecular mechanisms.

\section{Materials and methods}

Cell culture and reagents. The MG-63 human osteosarcoma cell line was purchased from the American Type Culture Collection (Manassas, VA, USA) and was authenticated as to genotype and phenotype by the supplier. Cells were cultured in $\alpha$-minimum essential medium (MEM) (Gibco; Thermo Fisher Scientific, Inc., Waltham, MA, USA) supplemented with $10 \%$ heat-inactivated fetal bovine serum (FBS; HyClone; GE Healthcare Life Sciences, Logan, UT, USA), 100 U/ml ampicillin (HyClone; GE Healthcare Life Sciences) and $100 \mu \mathrm{g} / \mathrm{ml}$ streptomycin (HyClone; GE Healthcare Life Sciences) at $37^{\circ} \mathrm{C}$ in a humidified atmosphere of $5 \% \mathrm{CO}_{2}$ (normoxic conditions). To establish hypoxic conditions, cells were incubated in a humidified atmosphere consisting of $3 \% \mathrm{O}_{2}$. Curcumin (Sigma-Aldrich; Merck Millipore, Darmstadt, Germany) was dissolved in dimethyl sulfoxide (DMSO; Sigma-Aldrich; Merck Millipore). The cells in the control group were treated with DMSO only. 3-(4,5-dimethyl-2-thiazolyl)-2,5-diphenyl-2-H-tetrazolium bromide (MTT) was purchased from Sigma-Aldrich; Merck Millipore.

Cell viability assay. MG-63 cells were seeded into 96-well plates at a density of $5 \times 10^{3}$ cells per well and treated with various concentrations $(0,5$ or $10 \mu \mathrm{M})$ of curcumin. The cells were cultured under normoxic or hypoxic conditions. At the indicated time points $(12,24,36$ or $48 \mathrm{~h})$, cell viability was assessed by the MTT assay according to the manufacturer's protocol, and the absorbance was measured at a wavelength of $490 \mathrm{~nm}$ using a multiwell microplate reader (Bio-Tek Instruments, Inc., Winooski, VT, USA).

Matrigel invasion assays. Transwell assays were performed using 8- $\mu \mathrm{m}$ Transwell chambers (EMD Millipore, Billerica, MA, USA) according to a protocol described previously (4). Briefly, the membrane in the upper chamber was coated with Matrigel ( $25 \mu \mathrm{g}$ per filter) $12 \mathrm{~h}$ prior to use. MG-63 cells were pretreated with curcumin for $24 \mathrm{~h}$ and suspended in $\alpha$-MEM containing $0.1 \%$ FBS. Cells $\left(5 \times 10^{4}\right)$ were added to the upper chamber of the Transwell plates, and the lower compartments were filled with $\alpha$-MEM containing $10 \%$ FBS. Assays were performed at $37^{\circ} \mathrm{C}$ in normoxic or hypoxic $\left(3 \% \mathrm{O}_{2}\right)$ conditions. Following incubation for $48 \mathrm{~h}$, the non-invasive cells were removed from the upper surface of the membrane using a cotton-tipped swab. Invading cells on the bottom surface of the filter were fixed with methanol and stained with $0.1 \%$ crystal violet. The invading cells were counted in ten representative fields (magnification, x200) under a light microscope (Nikon Corporation, Tokyo, Japan).

Notch1 cDNA transfection. The Notch1 expression plasmid was constructed by cloning the NICD-1 fragment into a pcDNA3.1 vector using the following primers: Forward, 5'-CACCATGGTGCTGCTGTCCCGCAAGCGCC-3' and reverse, 5'-TGCTTTAAATGCCACAGGAATGTGGG-3'. For overexpression of Notch1, MG-63 cells $\left(0.5 \times 10^{6} /\right.$ well $)$ were seeded into a 6-well plate for $24 \mathrm{~h}$ and subsequently transfected with empty vector or Notch1 expression plasmid (5 $\mu \mathrm{g}$ cDNA) using Lipofectamine ${ }^{\circledR}$ reagent (Invitrogen; Thermo Fisher Scientific, Inc.). Cells were incubated at $37^{\circ} \mathrm{C}$ for $24 \mathrm{~h}$ and the culture medium was replaced with fresh medium. After a further incubation for $48 \mathrm{~h}$, cell extracts were prepared and the expression levels of Notch1 were examined by reverse transcription-quantitative polymerase chain reaction (RT-qPCR) and western blotting.

$R T-q P C R$. Total RNA was prepared from cells using TRIzol ${ }^{\circledR}$ reagent (Invitrogen; Thermo Fisher Scientific, Inc.) according to the manufacturer's protocol. cDNA was subsequently synthesized from $5 \mu \mathrm{g}$ RNA using the Takara Reverse Transcription Reagent (Takara Bio, Inc., Otsu, Japan). Relative expression levels of the Notch1 gene transcript were determined by qPCR using the $\mathrm{SYBR}^{\circledR}$-Green Master mix (Takara Biotechnology Co., Ltd., Dalian, China) in the iQ5 Multicolor Real-Time PCR Detection system (Bio-Rad Laboratories, Inc., Hercules, CA, USA). The primer sequences were as follows: Forward, 5'-GAGGCGTGGCAGACTATGC-3' and reverse, 5'-CTTGTACTCCGTCAGCGTGA-3' for Notch1; forward, 5'-CATCACTATCGGCAATGAGC-3' and reverse, 5'-GAC AGCACTGTGTTGGCATA-3' for $\beta$-actin. The following amplification conditions were used: Predenaturation at $94^{\circ} \mathrm{C}$ for $4 \mathrm{~min}$, followed by 40 cycles of denaturation at $94^{\circ} \mathrm{C}$ for $30 \mathrm{sec}$, annealing at $60^{\circ} \mathrm{C}$ for $30 \mathrm{sec}$ and extension at $72^{\circ} \mathrm{C}$ for $30 \mathrm{sec}$. The relative expression levels of Notch1 mRNA transcripts to GAPDH were determined using the $2^{-\Delta \Delta C q}$ method as previously described (20).

Western blot analysis. Total proteins were prepared from cells using radioimmunoprecipitation assay lysis buffer (Beyotime Institute of Biotechnology, Guangzhou, China) and protein concentration was determined using the Bicinchoninic Acid Protein assay kit (Pierce; Thermo Fisher Scientific, Inc.) according to the manufacturer's protocol. Equal quantities $(25 \mu \mathrm{g})$ of protein were subjected to $10 \%$ SDS-PAGE and transferred to $0.22 \mu \mathrm{m}$ polyvinylidene difluoride membranes. The membranes were blocked using $5 \%$ non-fat milk powder at room temperature for $1 \mathrm{~h}$ and incubated with primary anti-Notch1 (1:800; rabbit; cat. no. 3439; Cell Signaling Technology, Inc., Danvers, MA, USA) or anti- $\beta$-actin $(1: 1,000$; rabbit; cat. no. 4970 ; Cell Signaling Technology, Inc.) or anti-HIF-1 $\alpha$ (1:500; rabbit; cat. no. BS3514; Bioworld Technology, Inc., St. Louis Park, MN, USA) antibodies overnight at $4^{\circ} \mathrm{C}$. Following washing, the membranes were incubated with goat anti-rabbit horseradish peroxidase (HRP)-conjugated secondary antibodies (1:5,000; cat. no. ab97051; Abcam, Cambridge, MA, USA) at room temperature for $2 \mathrm{~h}$. The bands were visualized using an Enhanced Chemiluminescence Detection system (GE Healthcare Life Sciences, Chalfont, UK). Quantity One ${ }^{\circledR}$ software (version 4.6.2; Bio-Rad Laboratories, Inc.) was used to analyze the densitometry of each band; $\beta$-actin served as an internal loading control.

Statistical analysis. Experiments were repeated three times with each sample analyzed in triplicate. The results are expressed as the mean \pm standard deviation. Differences 


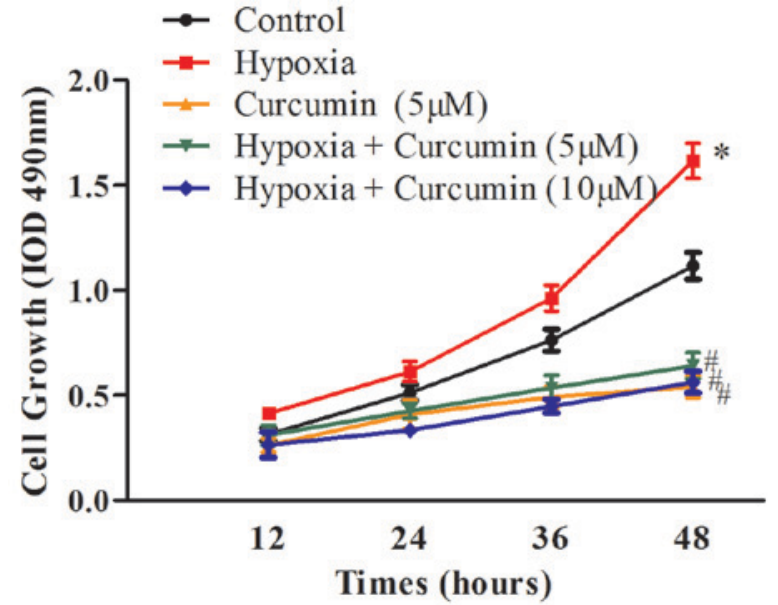

Figure 1. Curcumin suppresses the hypoxia-induced proliferation of MG-63 cells. MG-63 cells were seeded into 96-well plates and treated with various concentrations $(0,5$ or $10 \mu \mathrm{M})$ of curcumin. Cells were subsequently cultured in normoxic or hypoxic $\left(3 \% \mathrm{O}_{2}\right)$ conditions. At the indicated time points (12, 24,36 or $48 \mathrm{~h}$ ), cell viability in each group was assessed by an MTT assay. Data are expressed as the mean \pm standard deviation $(n=3)$. IOD, integrated optical density. ${ }^{*} \mathrm{P}<0.05$ vs. the control group; ${ }^{~} \mathrm{P}<0.05$ vs. the hypoxia group.

between groups were evaluated using a one-way analysis of variance followed by Dunnett's post hoc test. Statistical analysis was performed in SPSS software version 15.0 (SPSS, Inc., Chicago, IL, USA). $\mathrm{P}<0.05$ was considered to indicate a statistically significant difference.

\section{Results}

Curcumin inhibits hypoxia-induced proliferation of osteosarcoma cells. Firstly, the effects of curcumin on the viability of cancer cells under hypoxic conditions were examined. MG-63 osteosarcoma cells were treated with 5 or $10 \mu \mathrm{M}$ curcumin under normoxic or hypoxic conditions, for $12,24,36$ or $48 \mathrm{~h}$, and cell viability was assessed using an MTT assay. As presented in Fig. 1, cell growth was accelerated in hypoxic conditions compared with control normoxic conditions $(\mathrm{P}=0.032)$. Curcumin treatment $(5 \mu \mathrm{M})$ inhibited cell growth in normoxic conditions $(\mathrm{P}=0.028)$. Furthermore, hypoxia-induced cell proliferation was prevented by curcumin treatment at 5 and $10 \mu \mathrm{M}$ concentrations $(\mathrm{P}=0.016)$. These results indicated that curcumin may inhibit the growth of osteosarcoma cells in normoxic and hypoxic conditions.

Curcumin inhibits hypoxia-induced invasion of osteosarcoma cells. Cancer cells exposed to hypoxic conditions demonstrate enhanced invasiveness and metastasis $(21,22)$. To investigate the effect of curcumin on the invasiveness of the MG-63 osteosarcoma cell line, a Transwell assay was performed. As presented in Fig. 2, the number of invaded cells cultured in hypoxic conditions was significantly greater compared with control normoxic conditions $(\mathrm{P}=0.005)$. However, hypoxia-mediated cell invasiveness was markedly inhibited by curcumin treatment, which significantly reduced the number of invaded cells in a dose-dependent manner. These findings suggested that curcumin may inhibit the invasiveness of cancer cells under hypoxic conditions.
Curcumin inhibits hypoxia-induced Notchl upregulation. Previous studies indicated that Notch1 is required for the hypoxia-induced proliferation and invasion of cancer cells (23). The present study investigated whether curcumin has an effect on hypoxia-induced Notch1 upregulation in MG-63 cells. As presented in Fig. 3A, RT-qPCR revealed that the relative mRNA expression levels of Notch1 in cells cultured in hypoxic conditions were markedly greater compared with those from normoxic conditions $(\mathrm{P}=0.007)$. However, the hypoxia-induced Notch1 mRNA expression levels were markedly reduced by $5(\mathrm{P}=0.007)$ and $10 \mu \mathrm{M}(\mathrm{P}=0.003)$ curcumin. These observations were further supported at the protein level by western blotting (Fig. 3B). Treatment with curcumin markedly diminished the hypoxia-induced upregulation of the HIF-1 $\alpha$ and Notch1 proteins. Together, these data indicated that curcumin may inhibit hypoxia-induced Notch1 upregulation in a dose-dependent manner.

Overexpression of Notchl reduces curcumin-induced cell growth inhibition under hypoxia. To determine the underlying mechanisms of Notch1 in curcumin-inhibited cell growth under hypoxic conditions, MG-63 cells were transfected with the Notch1 cDNA. The mRNA and protein expression levels of Notch1 in MG-63 cells were detected by RT-qPCR and western blotting, respectively. As presented in Fig. 4A, RT-qPCR revealed that Notch1 mRNA expression levels were approximately 3-fold greater in Notch1 cDNA-transfected cells compared with cells transfected with an empty vector $(\mathrm{P}=0.0007)$. These results were supported by western blotting data (Fig. 4B). The effects of Notch1 overexpression on curcumin-mediated cell growth inhibition were subsequently assessed under hypoxia in MG-63 cells. Notch1 cDNA-transfected and empty vector-transfected control cells were cultured in the absence or presence of $10 \mu \mathrm{M}$ curcumin under normoxia, for 12, 24, 36 or $48 \mathrm{~h}$, and cell viability was assessed by an MTT assay. As presented in Fig. 4C, the promoted cell growth in hypoxia was prevented by curcumin treatment at a concentration of $10 \mu \mathrm{M}(\mathrm{P}=0.001)$. Cells transfected with Notch1 cDNA demonstrated increased cell growth compared with empty vector-transfected control cells under normoxia ( $\mathrm{P}=0.007)$. Notably, curcumin-inhibited cell growth in hypoxia was reversed by Notch1 overexpression $(\mathrm{P}=0.019)$. The Notch1 protein expression levels in each group were detected by western blotting (Fig. 4D). Collectively, these data indicated that Notch1 may be involved in curcumin-inhibited cell growth in hypoxia.

\section{Discussion}

Although osteosarcoma is a relatively rare type of malignant cancer, the high incidence in children and adolescents make it a major public health issue worldwide. In the past decade, despite progress in the understanding of osteosarcoma and the advent of multi-agent chemotherapy, there has been no significant improvement in prognosis for patients with osteosarcoma. Developments in molecular biology have provided insight into the molecular pathogenesis of osteosarcoma $(24,25)$. Previous studies $(5,26)$ have demonstrated that hypoxia is a common phenomenon within solid tumors, including osteosarcoma. Hypoxia-mediated upregulation of HIF-1 $\alpha$ may act on multiple 


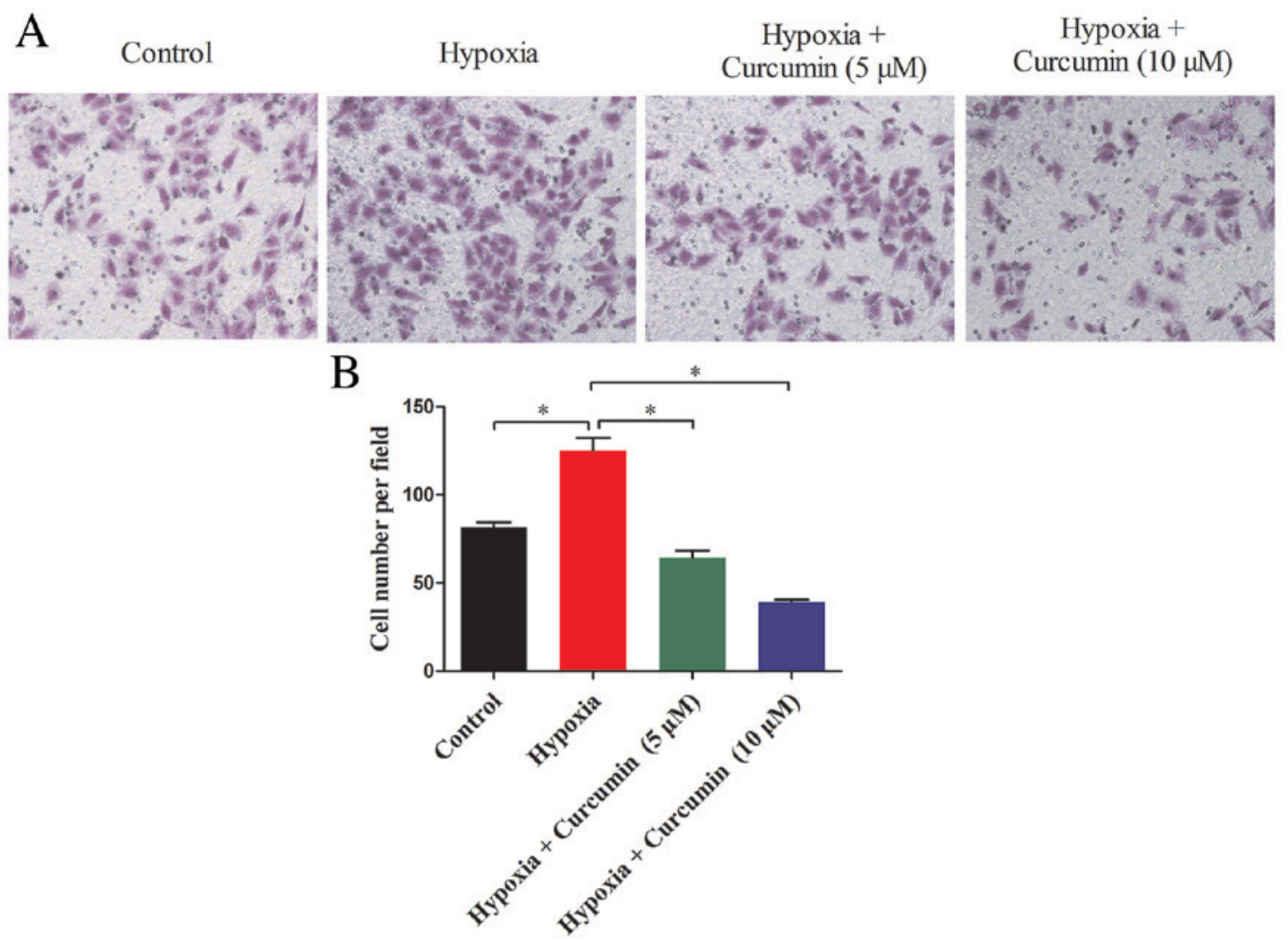

Figure 2. Curcumin ameliorates the hypoxia-enhanced invasiveness of MG-63 cells. (A) Curcumin (5 or $10 \mu \mathrm{M})$-pretreated MG-63 cells were seeded into a Matrigel-coated upper chamber Following exposure to hypoxic conditions for $48 \mathrm{~h}$, the invaded cells on the lower side of the membrane were stained using crystal violet. Cells cultured in normoxic conditions without curcumin served as a control. Images are representative of three independent experiments. Magnification, $x 200$. (B) The number of migrated cells was quantified by counting the cells from 10 random fields. Data are expressed as the mean \pm standard deviation $(\mathrm{n}=3) .{ }^{*} \mathrm{P}<0.05$

A

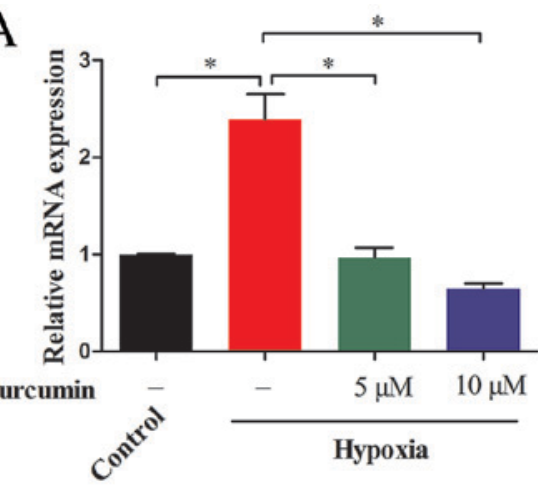

B

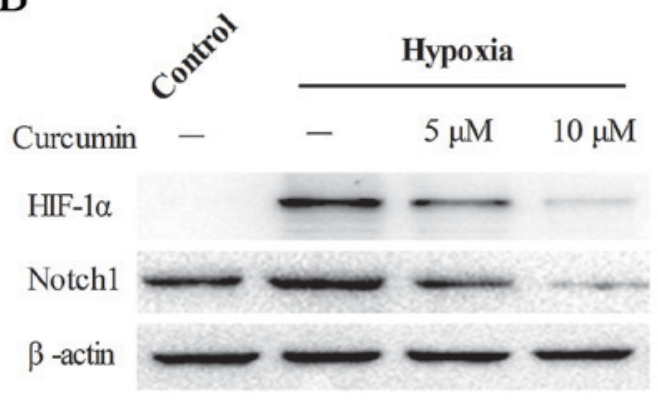

Figure 3. Curcumin prevents hypoxia-induced Notch1 upregulation in MG-63 cells. (A) MG-63 cells were exposed to various concentrations ( 0,5 or $10 \mu \mathrm{M})$ of curcumin and cultured in normoxic or hypoxic conditions for $24 \mathrm{~h}$. The mRNA expression levels of Notch1 were measured by reverse transcription-quantitative polymerase chain reaction; $\beta$-actin served as a normalization control. Data are expressed as the mean \pm standard deviation $(\mathrm{n}=3)$. $\mathrm{P}<0.05$. $(\mathrm{B})$ The protein expression levels of HIF-1 $\alpha$ and Notch1 were detected by western blotting using $\beta$-actin as an internal loading control. HIF-1 $\alpha$, hypoxia inducible factor $1 \alpha$.

downstream genes associated with tumor progression (27). HIF-1 $\alpha$ overexpression is a frequent event in osteosarcoma and has been identified as an independent prognostic biomarker in osteosarcoma (28), indicating that hypoxia is a feature of osteosarcoma. Therefore, it may be more relevant to examine the response of osteosarcoma to chemotherapeutics under hypoxic conditions.

Evidence from experimental and clinical studies have indicated a critical role for hypoxia in the malignant progression of solid tumors (27). Hypoxia has become a central issue in tumor physiology and cancer treatment due to its multiple roles in cancer cell genomic instability (29), angiogenesis (30), invasiveness (31), metastasis (32), resistance to cell death (33), metabolism reprogramming (34), chemoresistance (35) and radioresistance (36). A hypoxic microenvironment has been confirmed by histological studies of osteosarcoma specimens (37). It was reported that elevated HIF-1 $\alpha$ protein expression levels were associated with shortened disease-free survival and treatment resistance in osteosarcoma patients (6). In addition, a recent study demonstrated that osteosarcoma 
A

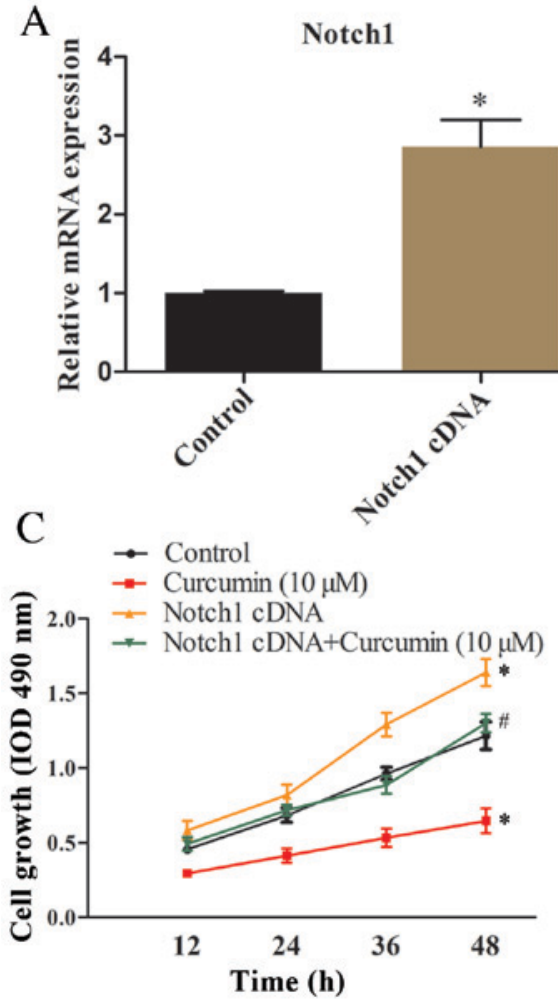

B

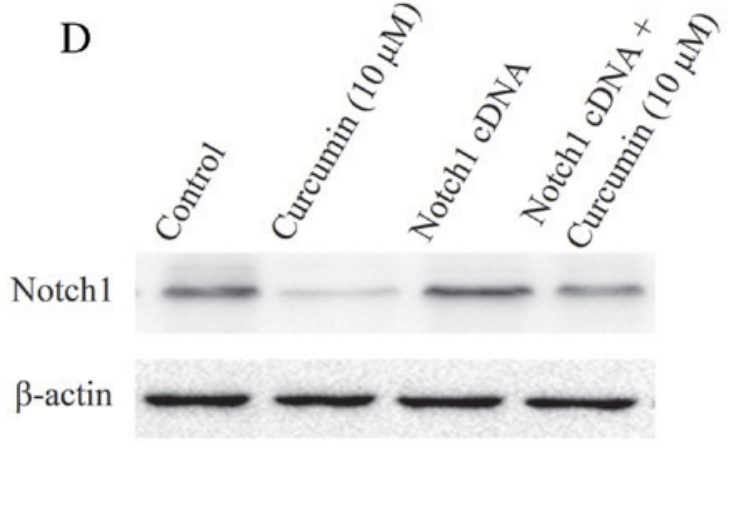

Figure 4. Overexpression of Notch1 reverses curcumin-inhibited proliferation of MG-63 cells under hypoxic conditions. MG-63 cells were transfected with Notch1 cDNA. After 48 h, the (A) mRNA and (B) protein expression levels of Notch1 in MG-63 were detected by reverse transcription-quantitative polymerase chain reaction and western blot analysis, respectively. (C) Notch1 cDNA-transfected and empty vector-transfected control cells were cultured in the absence or presence of $10 \mu \mathrm{M}$ curcumin in hypoxic $\left(3 \% \mathrm{O}_{2}\right)$ conditions. At 12, 24, 36 or $48 \mathrm{~h}$, cell viability in each group was assessed by an $\mathrm{MTT}$ assay. $\mathrm{P}<0.05$ vs. the control group; ${ }^{\#} \mathrm{P}<0.05$ vs. the curcumin $(10 \mu \mathrm{M})$ group. (D) The protein expression levels of Notch1 in each group were assessed by western blotting; $\beta$-actin served as an internal loading control. Data are expressed as the mean \pm standard deviation $(n=3)$. IOD, integrated optical density.

cells exhibited enhanced proliferation and invasiveness when exposed to hypoxic conditions (38). Consistent with this, the present study observed that the proliferation and invasiveness of MG-63 cells were markedly promoted by hypoxic conditions.

A previous study indicated that curcumin is a potent anticancer agent, which acts by targeting multiple cell signaling pathways involved in cancer progression (16). To date, various anti-cancer effects of curcumin have been revealed, including its ability to suppress proliferation, induce apoptosis and inhibit the invasion and metastasis of cancer cells (39). However, previous studies were primarily focused on the anticancer effects of curcumin under normoxic conditions, rather than focusing on its anticancer effects under hypoxic conditions. Duan et al (40) reported that curcumin may inhibit hypoxia-induced proliferation and epithelial-mesenchymal transition of hepatic carcinoma cells. This study used the chemical $\mathrm{CoCl}_{2}$ to establish hypoxic conditions, which is a poor reflection of real hypoxic conditions, although $\mathrm{CoCl}_{2}$ may induce HIF-1 $\alpha$ accumulation in cancer cells. In the present study, a culture condition containing $3 \% \mathrm{O}_{2}$ was used to examine the effects of curcumin on osteosarcoma cell proliferation and invasion. These results demonstrated that curcumin may inhibit hypoxia-induced proliferation and invasion of osteosarcoma cells. This suggested that curcumin may serve pivotal roles in tumor suppression under normoxic and hypoxic conditions.

Notch signaling is a highly conserved cell signaling system involved in normal organ development. Recent studies $(41,42)$ have suggested that the Notch1 signaling pathway serves a critical role in osteosarcoma pathogenesis, development, invasion and metastasis, which indicates that Notch1 is a potential therapeutic target in osteosarcoma. In the present study, in addition to enhanced proliferation and invasiveness, the Notch1 expression levels in MG-63 cells were markedly increased by hypoxia treatment. Furthermore, curcumin, which has been revealed to inhibit hypoxia-induced HIF-1 $\alpha$ expression, may suppress the expression levels of Notch1. These results indicated that Notch1 may be a downstream gene of HIF-1 $\alpha$ in osteosarcoma cells and suggested that curcumin may serve as a potential anticancer agent for the treatment of osteosarcoma.

In conclusion, the current study demonstrated that the MG-63 osteosarcoma cell line exhibited increased rates of proliferation and enhanced invasiveness upon exposure to hypoxic conditions. However, the effects induced by hypoxia in MG-63 cells were prevented by curcumin treatment. Further investigation revealed that curcumin may inhibit the Notch1 upregulation induced by hypoxia. Overexpression of Notch1 by Notch1 cDNA transfection ameliorated curcumin-inhibited MG-63 cell growth under hypoxic conditions. Taken together, the results of the present study revealed that curcumin may suppress the growth of osteosarcoma cells in hypoxia via inhibition of Notch1 signaling.

\section{Acknowledgements}

The authors thank Medjaden Bioscience Limited (Hong Kong, China) for assisting in the preparation of the manuscript. 


\section{References}

1. Bacci G, Longhi A, Bertoni F, Briccoli A, Versari M, Pignotti E and Picci P: Bone metastases in osteosarcoma patients treated with neoadjuvant or adjuvant chemotherapy: The Rizzoli experience in 52 patients. Acta Orthop 77: 938-943, 2006.

2. Bielack SS, Kempf-Bielack B, Delling G, Exner GU, Flege S, Helmke K, Kotz R, Salzer-Kuntschik M, Werner M, Winkelmann W, et al: Prognostic factors in high-grade osteosarcoma of the extremities or trunk: An analysis of 1,702 patients treated on neoadjuvant cooperative osteosarcoma study group protocols. J Clin Oncol 20: 776-790, 2002.

3. Ruan K, Song G and Ouyang G: Role of hypoxia in the hallmarks of human cancer. J Cell Biochem 107: 1053-1062, 2009.

4. Tan C, Zhang L, Cheng X, Lin XF, Lu RR, Bao JD and Yu HX: Curcumin inhibits hypoxia-induced migration in K1 papillary thyroid cancer cells. Exp Biol Med (Maywood) 240: 925-935, 2015.

5. Mizobuchi H, Garcia-Castellano JM, Philip S, Healey JH and Gorlick R: Hypoxia markers in human osteosarcoma: An exploratory study. Clin Orthop Relat Res 466: 2052-2059, 2008.

6. Chen Y, Wang CM, Shi YQ and Yang Y: Expression of hypoxia-inducible factor 1alpha in osteosarcoma and its value in predicting chemosensitivity. Zhonghua Zhong Liu Za Zhi 34 899-904, 2012 (In Chinese).

7. Yang QC, Zeng BF, Dong Y, Shi ZM, Jiang ZM and Huang J: Overexpression of hypoxia-inducible factor-1alpha in human osteosarcoma: Correlation with clinicopathological parameters and survival outcome. Jpn J Clin Oncol 37: 127-134, 2007.

8. Al-Hussaini H, Subramanyam D, Reedijk M and Sridhar SS: Notch signaling pathway as a therapeutic target in breast cancer. Mol Cancer Ther 10: 9-15, 2011.

9. Dong Y, Jesse AM, Kohn A, Gunnell LM, Honjo T, Zuscik MJ, O'Keefe RJ and Hilton MJ: RBPjkappa-dependent Notch signaling regulates mesenchymal progenitor cell proliferation and differentiation during skeletal development. Development 137: 1461-1471, 2010

10. Qiang L, Wu T, Zhang HW, Lu N, Hu R, Wang YJ, Zhao L, Chen FH, Wang XT, You QD and Guo QL: HIF-1a is critical for hypoxia-mediated maintenance of glioblastoma stem cells by activating Notch signaling pathway. Cell Death Differ 19: 284-294, 2012

11. Singh S and Khar A: Biological effects of curcumin and its role in cancer chemoprevention and therapy. Anticancer Agents Med Chem 6: 259-270, 2006.

12. Panchal HD, Vranizan K, Lee CY, Ho J, Ngai J and Timiras PS: Early anti-oxidative and anti-proliferative curcumin effects on neuroglioma cells suggest therapeutic targets. Neurochem Res 33: 1701-1710, 2008.

13. Kurup VP and Barrios CS: Immunomodulatory effects of curcumin in allergy. Mol Nutr Food Res 52: 1031-1039, 2008.

14. Kim DC, Ku SK and Bae JS: Anticoagulant activities of curcumin and its derivative. BMB Rep 45: 221-226, 2012.

15. Dou X, Fan C, Wo L, Yan J, Qian Y and Wo X: Curcumin up-regulates LDL receptor expression via the sterol regulatory element pathway in HepG2 cells. Planta Med 74: 1374-1379, 2008.

16. Shishodia S, Chaturvedi MM and Aggarwal BB: Role of curcumin in cancer therapy. Curr Probl Cancer 31: 243-305, 2007.

17. Chang YJ, Huang CY, Hung CS, Chen WY and Wei PL: GRP78 mediates the therapeutic efficacy of curcumin on colon cancer. Tumour Biol 36: 633-641, 2015.

18. Ye M, Zhang J, Zhang J, Miao Q, Yao L and Zhang J: Curcumin promotes apoptosis by activating the $\mathrm{p} 53-\mathrm{miR}-192-5 \mathrm{p} / 215-\mathrm{XIAP}$ pathway in non-small cell lung cancer. Cancer Lett 357: 196-205, 2015.

19. Amin AR, Haque A, Rahman MA, Chen ZG, Khuri FR and Shin DM: Curcumin induces apoptosis of upper aerodigestive tract cancer cells by targeting multiple pathways. PLoS One 10: e0124218, 2015.

20. Schmittgen TD and Livak KJ: Analyzing real-time PCR data by the comparative C (T) method. Nat Protoc 3: 1101-1108, 2008.

21. Zhao X, Gao S, Ren H, Sun W, Zhang H, Sun J, Yang S and Hao J: Hypoxia-inducible factor-1 promotes pancreatic ductal adenocarcinoma invasion and metastasis by activating transcription of the actin-bundling protein fascin. Cancer Res 74: 2455-2464, 2014.
22. Liu N, Wang Y, Zhou Y, Pang H, Zhou J, Qian P, Liu L and Zhang H: Kruppel-like factor 8 involved in hypoxia promotes the invasion and metastasis of gastric cancer via epithelial to mesenchymal transition. Oncol Rep 32: 2397-2404, 2014.

23. Sahlgren C, Gustafsson MV, Jin S, Poellinger L and Lendahl U: Notch signaling mediates hypoxia-induced tumor cell migration and invasion. Proc Natl Acad Sci USA 105: 6392-6397, 2008.

24. Broadhead ML, Clark JC, Myers DE, Dass CR and Choong PF: The molecular pathogenesis of osteosarcoma: A review. Sarcoma 2011: 959248, 2011

25. He JP, Hao Y, Wang XL, Yang XJ, Shao JF, Guo FJ and Feng JX: Review of the molecular pathogenesis of osteosarcoma. Asian Pac J Cancer Prev 15: 5967-5976, 2014.

26. El NA, Clarkson P, Zhang F, Mathers J, Tognon C and Sorensen PH: Expression and stability of hypoxia inducible factor 1a in osteosarcoma. Pediatr Blood Cancer 59: 1215-1222, 2012.

27. Koh MY, Spivak-Kroizman TR and Powis G: HIF-1alpha and cancer therapy. Recent Results Cancer Res 180: 15-34, 2010.

28. Zhao $\mathrm{H}, \mathrm{Wu} \mathrm{Y}$, Chen $\mathrm{Y}$ and Liu H: Clinical significance of hypoxia-inducible factor 1 and VEGF-A in osteosarcoma. Int J Clin Oncol 20: 1233-1243, 2015.

29. Nelson DA, Tan TT, Rabson AB, Anderson D, Degenhardt K and White E: Hypoxia and defective apoptosis drive genomic instability and tumorigenesis. Genes Dev 18: 2095-2107, 2004.

30. Moeller BJ, Cao Y, Vujaskovic Z, Li CY, Haroon ZA and Dewhirst MW: The relationship between hypoxia and angiogenesis. Semin Radiat Oncol 14: 215-221, 2004.

31. Gu Q, He Y, Ji J, Yao Y, Shen W, Luo J, Zhu W, Cao H, Geng Y, $\mathrm{Xu} \mathrm{J}$, et al: Hypoxia-inducible factor la (HIF-1a) and reactive oxygen species (ROS) mediates radiation-induced invasiveness through the SDF-1a/CXCR4 pathway in non-small cell lung carcinoma cells. Oncotarget 6: 10893-10907, 2015.

32. Lu X and Kang Y: Hypoxia and hypoxia-inducible factors: Master regulators of metastasis. Clin Cancer Res 16: 5928-5935, 2010.

33. Kim M, Park SY, Pai HS, Kim TH, Billiar TR and Seol DW: Hypoxia inhibits tumor necrosis factor-related apoptosis-inducing ligand-induced apoptosis by blocking Bax translocation. Cancer Res 64: 4078-4081, 2004.

34. Bel Aiba RS, Dimova EY, Görlach A and Kietzmann T: The role of hypoxia inducible factor-1 in cell metabolism-a possible target in cancer therapy. Expert Opin Ther Targets 10: 583-599, 2006.

35. Selvendiran K, Bratasz A, Kuppusamy ML, Tazi MF, Rivera BK and Kuppusamy P: Hypoxia induces chemoresistance in ovarian cancer cells by activation of signal transducer and activator of transcription 3. Int J Cancer 125: 2198-2204, 2009.

36. Zou YM, Hu GY, Zhao XQ, Lu T, Zhu F, Yu SY and Xiong H: Hypoxia-induced autophagy contributes to radioresistance via c-Jun-mediated Beclin1 expression in lung cancer cells. J Huazhong Univ Sci Technolog Med Sci 34: 761-767, 2014.

37. Guan G, Zhang Y, Lu Y, Liu L, Shi D, Wen Y, Yang L, Ma Q Liu T, Zhu X, et al: The HIF-1a/CXCR4 pathway supports hypoxia-induced metastasis of human osteosarcoma cells. Cancer Lett 357: 254-264, 2015.

38. Sun Y, Wang H, Liu M, Lin F and Hua J: Resveratrol abrogates the effects of hypoxia on cell proliferation, invasion and EMT in osteosarcoma cells through downregulation of the HIF-1 $\alpha$ protein. Mol Med Rep 11: 1975-1981, 2015.

39. Shehzad A, Wahid F and Lee YS: Curcumin in cancer chemoprevention: Molecular targets, pharmacokinetics, bioavailability, and clinical trials. Arch Pharm (Weinheim) 343: 489-499, 2010.

40. Duan W, Chang Y, Li R, Xu Q, Lei J, Yin C, Li T, Wu Y, Ma Q and Li X: Curcumin inhibits hypoxia inducible factor-1 $\alpha$-induced epithelial-mesenchymal transition in HepG2 hepatocellular carcinoma cells. Mol Med Rep 10: 2505-2510, 2014.

41. Wang L, Jin F, Qin A, Hao Y, Dong Y, Ge S and Dai K: Targeting Notch1 signaling pathway positively affects the sensitivity of osteosarcoma to cisplatin by regulating the expression and/or activity of Caspase family. Mol Cancer 13: 139, 2014.

42. Tao J, Jiang MM, Jiang L, Salvo JS, Zeng HC, Dawson B, Bertin TK, Rao PH, Chen R, Donehower LA, et al: Notch activation as a driver of osteogenic sarcoma. Cancer Cell 26: 390-401, 2014. 